\title{
Effects of lightning impulse front time on substation grounding system performance
}

\author{
Muhammad Adnan ${ }^{1}$, Zulkurnain Abdul-Malek ${ }^{2}$, Nur Syazwani Mohd Din ${ }^{3}$ \\ Muhammad Irfan Jambak ${ }^{4}$, Zainuddin Nawawi ${ }^{5}$, Muhammad Abu Bakar Sidik ${ }^{6}$ \\ ${ }^{1,2,3}$ Institute of High Voltage and High Current, School of Electrical Engineering, \\ Faculty of Engineering, Universiti Teknologi Malaysia, Malaysia \\ ${ }^{4,5,6}$ Department of Electrical Engineering, Faculty of Engineering, Universitas Sriwijaya, Indonesia
}

\section{Article Info}

\section{Article history:}

Received May 7, 2020

Revised Jun 20, 2020

Accepted Jul 8, 2020

\section{Keywords:}

Grounding grid Ground potential rise Touch voltage

Step voltage

Front time

\begin{abstract}
The role of the grounding system in the safety of the power system and protection of personnel is obvious during an unexpected short circuit or lightning discharge at the substation. The aim of this work is to analyze the effects of several parameters: lightning impulse front time, soil resistivity and types of grid materials on the grounding system of the Substation. The ground potential rise (GPR), touch voltage and step voltage of a $50 \mathrm{~m} \mathrm{x}$ $60 \mathrm{~m}$ grounding grid buried at a depth of $0.5 \mathrm{~m}$ were computed using CDEGS when injected by impulse with different front times. Results show that the shorter the front time of lightning impulse waveform, the higher the value of GPR, touch voltage and step voltage. Meanwhile, when the value of soil resistivity is increased, the value of GPR, touch voltage and step voltage is also increased. Lastly, different types of grid conductor materials give different values of GPR, touch voltage and step voltage. However, it can be said that the differences are too small to be of any significance.
\end{abstract}

Copyright @ 2020 Institute of Advanced Engineering and Science. All rights reserved.

Corresponding Author:

Zulkurnain Abdul-Malek, Institute of High Voltage and High Current, Universiti Teknologi Malaysia, 81310 Johor Bahru, Malaysia. Email: zulkurnain@utm.my

\section{INTRODUCTION}

The role of a proper grounding system of the substation is very vital. The role of the grounding system comes into play for the protection of power grid equipment's and personnel safety, During normal and in an unexpected lightning interruption on substation. Lightning impulse on the substation can be classified into lightning impulse current waveform and lightning impulse voltage waveform. Two types of lightning impulse current waveforms which are direct lightning current and indirect lightning current waveform. the level of voltages should be made minimum as possible to ensure the reliability and safety of the substation.

When designing the grounding system of a substation, Ground potential rise (GPR), touch voltage, and step voltage are considered as an important parameter to be observed and analyzed. A good design should maintain the value of touch voltage and step voltage under the safety limits. In addition, the grounding system design should have a very low ground resistance with a tolerance of touch voltage and step voltage limits [1]. A higher than expected potential rise can cause harm to the safety of a person nearby and also to the equipment of the substation. 
Previous studies have proven that the transient characteristics of a grounding grid were far more different than those at power frequency because of associated inductance and soil ionization under highfrequency transients [2-7]. Often, the shape of the lightning impulse can affect the resultant voltage profiles, namely, the touch potential, the step potential and the GPR of the grounding system. Lian et al. [4] studied the effects of several parameters on the ground impedance, based on two lightning impulse current shapes, namely $2.6 / 50 \mu$ s and $8 / 20 \mu$ s currents. Several authors $[2,4,7,8]$ have reported the influence of the lightning impulse points of injection (such as at the grid corner and center points) on the grounding grid performance. Tian et al. [2] carried out a study on the lightning transient characteristics of a $500 \mathrm{kV}$ substation grounding grid meanwhile Lian et al. [4] focus their study on the $110 \mathrm{kV}$ substation.

Despite the above studies, the effects of other injection points of the grid at a transmission voltage level typical in Malaysia, namely $275 \mathrm{kV}$, on the transient performance of the grid is desired to be known. Further examination needs to be done to study the effects of soil resistivity and grounding grid materials. A better understanding of the performance of the grounding system design under the lightning impulse current can help in a better design of a grounding system.

\section{RESEARCH METHOD}

The effects of grid sizes on the grid performance in terms of grid potential rises were well studied [9-21]. In this work, a constant grid size was chosen (5 m spacing). The grounding grid model was modelled using HIFREQ module of the CDEGS software. The grounding grid was designed with a total area of $50 \mathrm{~m} \times 50 \mathrm{~m}$, at a depth of $0.5 \mathrm{~m}$, and using conductors with a radius of $0.1 \mathrm{~mm}$. The inter conductor distance is $5.0 \mathrm{~m}$. The soil resistivity was fixed at $100 \Omega$.m. Figure 1 shows the modelled grounding used in the simulation work.

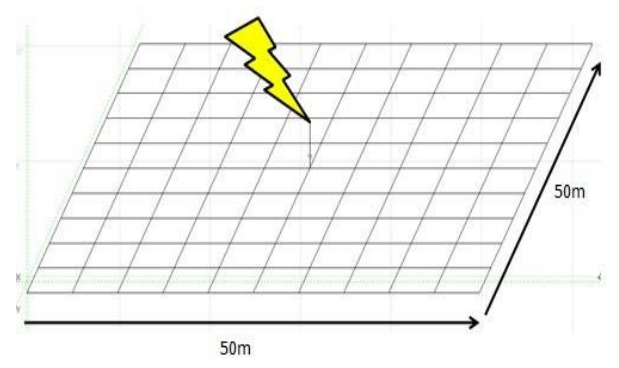

Figure 1. Grounding grid model

The input waveforms were then designed. The lightning impulse voltage front time waveform was varied to analyze the effects of front time waveform on the grounding grid model. A double exponential lightning type signal with the amplitude maintained constant at $30 \mathrm{kA}$ was used. Three impulse shapes defined by the front time were simulated. These are $1.2 / 50 \mu \mathrm{s}, 5 / 50 \mu \mathrm{s}$, and $10 / 50 \mu \mathrm{s}$ waveforms. Since CDEGS is a frequency-based software, the fast Fourier transform (FFT) module was used to convert the time domain waveform into its equivalent frequency domain components. Figures 2 to 4 show the three input waveforms used in the simulations.

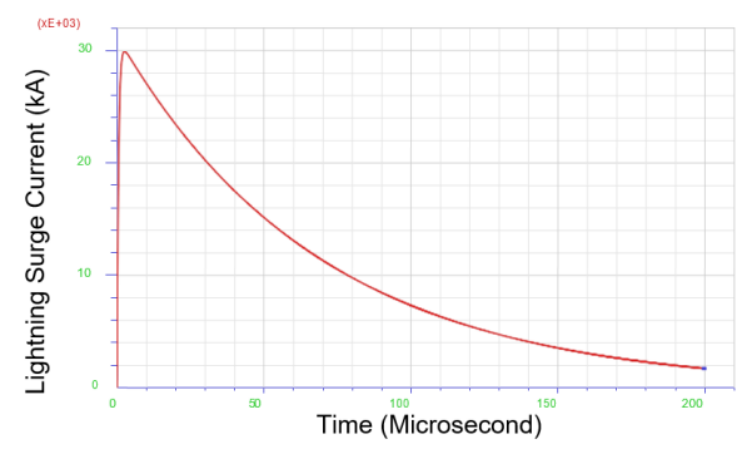

Figure 2. $30 \mathrm{kA}$ peak, 1.2/50 $\mu$ s lightning current

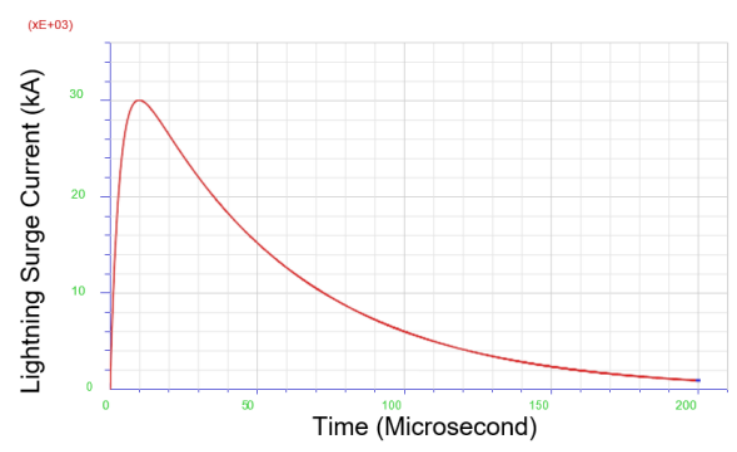

Figure 3. $30 \mathrm{kA}$ peak, $5 / 50 \mu$ s lightning current 


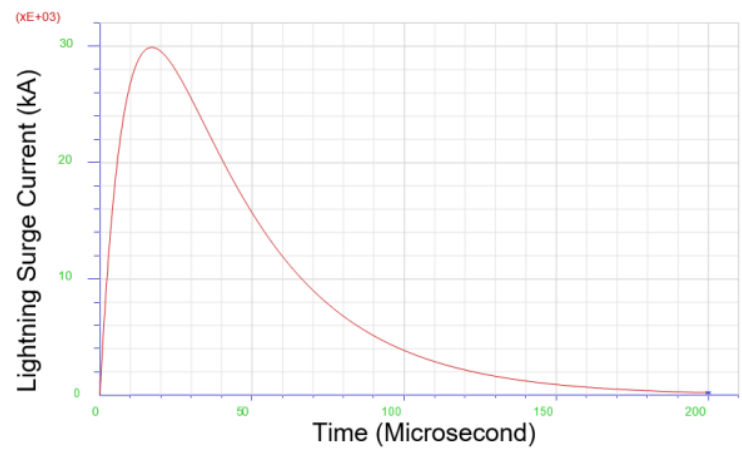

Figure 4. $30 \mathrm{kA}$ peak, 10/50 $\mu$ s lightning current

\section{RESULTS AND ANALYSIS}

The effects of three different parameters which are The lightning current front time, the soil resistivity and the type of grid conductor on the GPR, touch voltage and step voltage were investigated using the frequency domain HIFREQ module. The module automatically computes the frequency response of all equivalent frequency components of the lightning current obtained using the FFT module. The response in time domain was then obtained using the inverse fast Fourier transform (IFFT) module. Several observation points were made including at the middle point of the grounding grid.

\subsection{Effects of lightning impulse front time}

The chosen injection and observation points are both in the middle of the grounding grid. A $30 \mathrm{kA}$, $1.2 / 50 \mu$ s current was injected at the central location and the soil resistivity was fixed at $100 \Omega$.m. A copper type conductor was used. The effects of the current front time on the maximum GPR, touch voltage and step voltage at that point were analyzed. Figure 5 to 7 shows the effects of the current front time on the maximum GPR, touch voltage and step voltage.

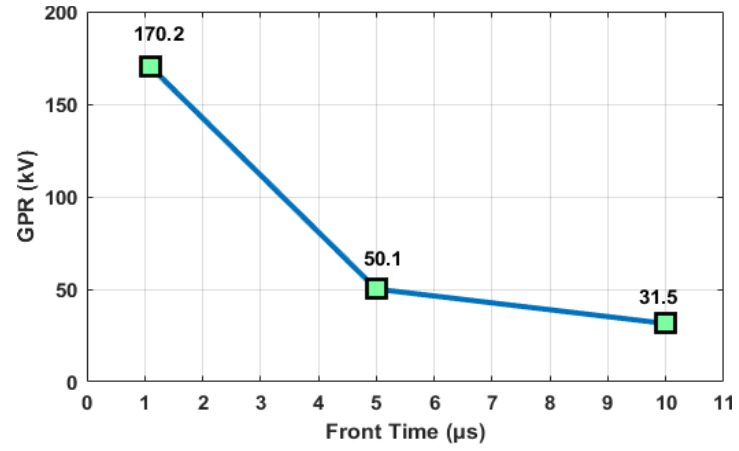

Figure 5. Variation of Maximum GPR with front time

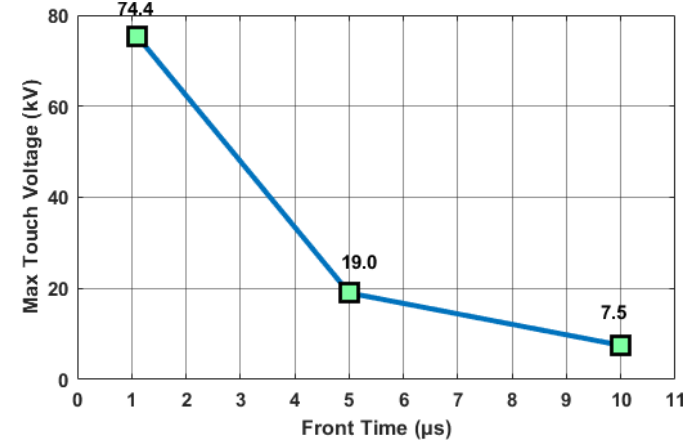

Figure 6. Variation of maximum touch voltage with front time

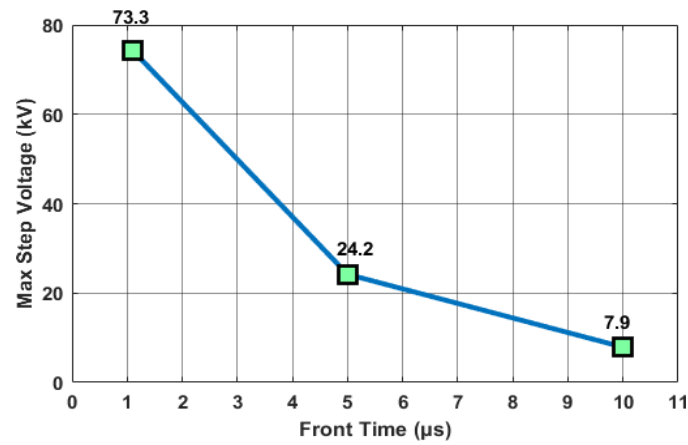

Figure 7. Variation of maximum step voltage with the front time 
The results show that a faster current front causes the potential rise to be higher than the slower fronts. If the grounding grid was designed using AC $50 \mathrm{~Hz}$ frequency, the expected potential rises would be much smaller. If the design did take consideration of the transient effects, the choice of front time plays an important role. It is not unusual for lightning current front time to be as fast as $1 \mu$ s, and hence consideration of this fast front transient should be considered when designing a grounding grid.

\subsection{The effects of soil resistivity}

The maximum GPR, touch voltage and step voltage on the grounding grid model were analyzed by varying the value of the soil resistivity from $100 \Omega . \mathrm{m}$ to $300 \Omega . \mathrm{m}$. A $30 \mathrm{kA}, 1.2 / 50 \mu$ s current was used. Both the injection point and the observation point are at the centre of the grid. The observed results are shown in Figures 8 to 10.

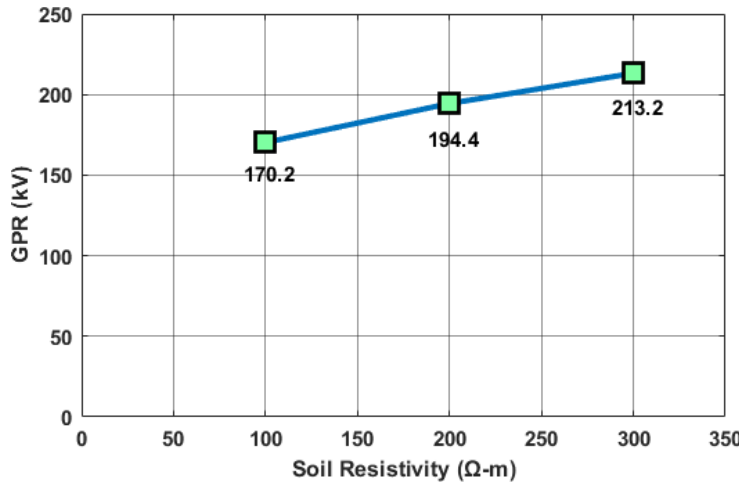

Figure 8. Variation of maximum GPR with soil resistivity

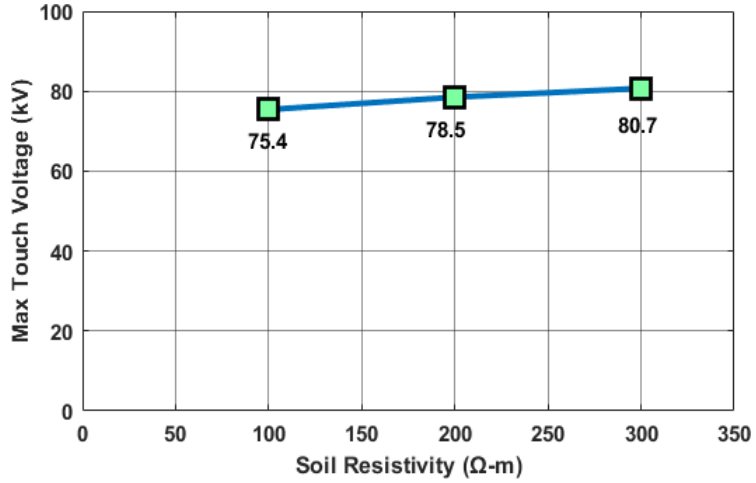

Figure 9. Variation of maximum touch voltage with soil resistivity

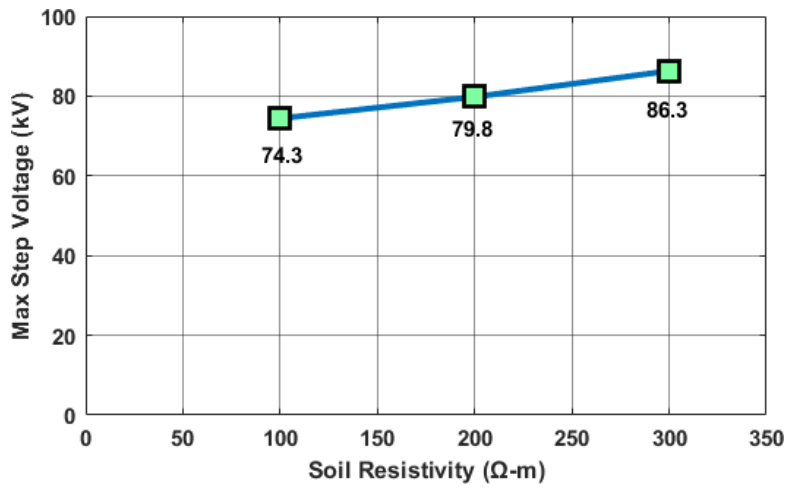

Figure 10. Variation of maximum step voltage with soil resistivity

It can be clearly seen that GPR, touch and step voltages increase as the soil resistivity increases. This is somewhat expected since the potential rise is proportional to the equivalent resistance of the grid which is directly related to the soil resistivity. In other words, there is a risk to the personnel safety if the soil is having its resistivity rises to values higher than the initial value used in the grounding grid design.

\subsection{The effects of grid conductor material}

Three different types of grid conductor materials were simulated. These materials includes Pure Copper, pure Iron and Steel Rail with the resistivity of $1 \Omega . \mathrm{m}, 1.64 \Omega . \mathrm{m}$, and $5.7 \Omega . \mathrm{m}$, respectively. These give a corresponding relative conductivity for pure copper, pure iron and steel rail as $100 \%, 17 \%$, and $15 \%$, respectively. A constant soil resistivity value of $100 \Omega . \mathrm{m}$ was maintained during the simulation while the $30 \mathrm{kA}$ peak, $1.2 / 50 \mu$ s type of lightning impulse current was used. The observation point was at the center of the grounding grid. Figures 11 to 13 shows the variation of GPR, maximum touch voltage and maximum step voltage with respect to the grind conductor materials. 


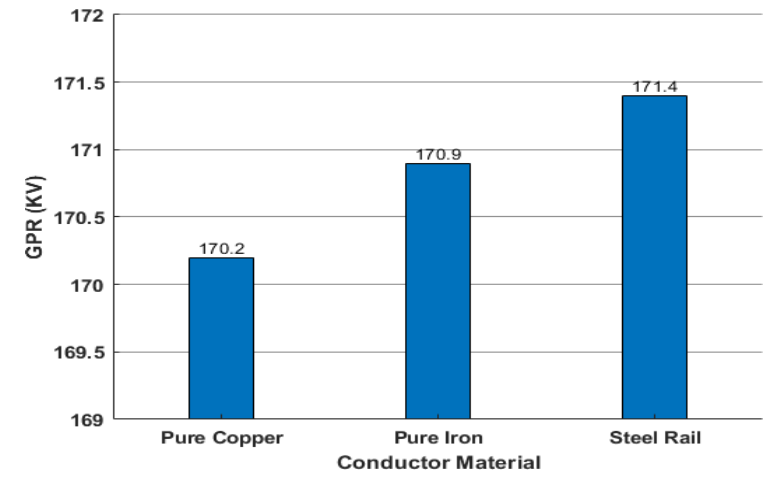

Figure 11. Variation of maximum GPR with grid conductor material

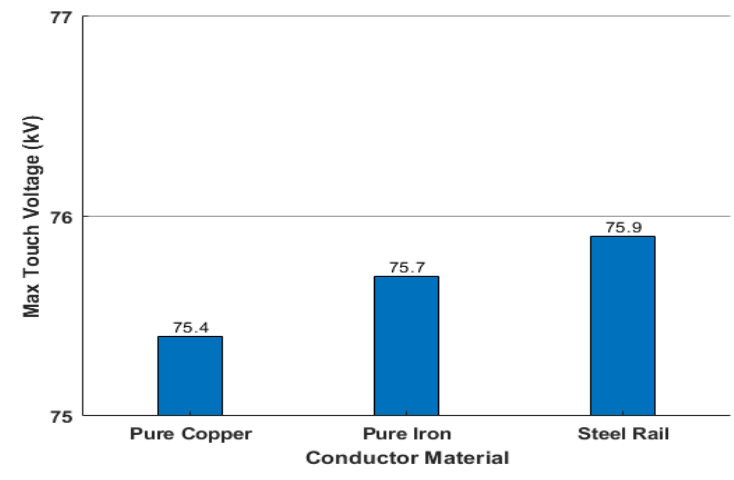

Figure 12. Variation of maximum touch voltage with grid conductor material

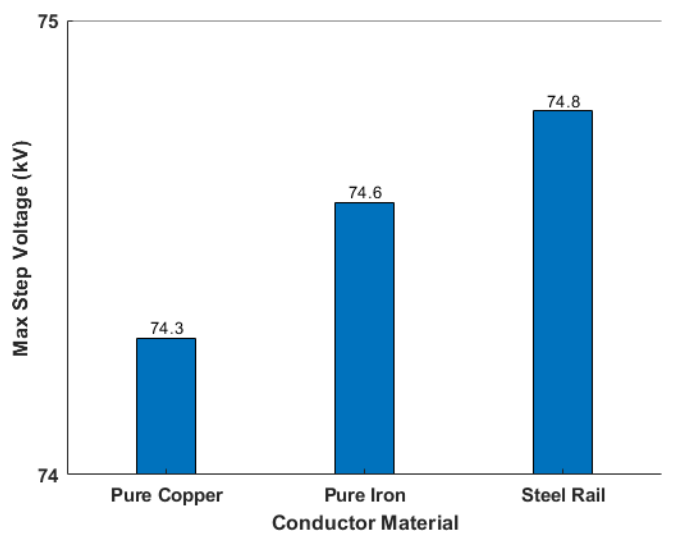

Figure 13. Variation of maximum step voltage with grid conductor material

Based on Figures 11 to 13, the steel rail has the highest value of GPR, touch voltage and step voltage followed by pure iron and pure copper. In other words, a grid made with conductors having larger resistivity results in a higher GPR, touch voltage and step voltage. However, the relative differences in the potential between all conductor types and hence their effect on safety can be said as negligible. The above results show that several parameters can influence the grid transient performance. Other parameters may also influence the grid performance. It is well known that soil behaves differently when subjected to large transient currents such as having ionization phenomenon within the soil grains [22-26]. The effects of soil ionization were not however modelled when the design is based on AC $50 \mathrm{~Hz}$ frequency or even short circuit current. This shows that modeling and properly design a grounding grid including its transient response is a must for the purpose of ultimate substation or lightning protected building safety.

\section{CONCLUSION}

As a conclusion the shorter the lightning impulse front time, the higher the value of GPR, touch voltage and step voltage. On the other hand, the higher the values of soil resistivity, the higher are the GPR, touch voltage and step voltage. Thus, when installing the grounding grid, the soil should have not only a very low resistivity but also a more or less constant or lower values throughout the substation or grounding grid life. The grid conductor material should have a very low resistivity value, and in this study, it was found that pure copper gives the best grid performance. Other parameters may also influence the grid performance. It is well known that soil behaves differently when subjected to large transient currents such as having ionization phenomenon within the soil grains. The effects of soil ionization purpose not however modelled. This can be the subject of future studies.

\section{ACKNOWLEDGMENT}

Authors wish to thank Malaysian Ministry of Education (4F828), Universiti Teknologi Malaysia (18H10 \& 01M44) and Universitas Sriwijaya (4B345 \& 4B279) for the financial support. 


\section{REFERENCES}

[1] M. Mondal, R.K Jarial, S. Ram, and G. Singh, "Design and analysis of substation grounding grid with and without considering seasonal factor using EDSA software," International Journal of Innovations in Engineering and Technology, pp. 64-77, April 2013.

[2] C. Tian, Y. Zang, L. Cai, J. Wang, S. Huang and Y. Wang, "Lighting transient characteristics of a 500-kV substation grounding grid," $7^{T H}$ Asia-Pacific International Conference on Lightning, pp. 711-715, 2011.

[3] Y. Tu, J. He, and R. Zeng, "Lightning Impulse performances of grounding devices covered with low- resistivity materials," IEEE Transactions on Power Delivery, vol. 21, no. 3, pp. 1706-1713, 2006.

[4] D. Lian, Z. Bo, H. Jinliang, X. Leishi, and L.Qian, "Experimental study on transient characteristics of grounding grid for substation," IEEE International Conference on Lightning Protection (ICLP), pp. 1-6, 2016.

[5] S. Nikolovski, G. Knezevic, and Z. Baus, "Assessment of step and touch voltages for different multilayer soil models of complex grounding grid," International Journal of Electrical and Computer Engineering, vol. 6, no. 4, pp. 1441-1455, 2016.

[6] L.D. Grcev, and M. Heimbach, "Frequency dependent and transient characteristics of substation grounding systems," IEEE Transaction on Power Delivery, vol. 12, no. 1, pp. 172-178, 1997.

[7] R. Zeng, X. Gong, J. He, B. Zhang, and Y. Gao, "Lightning impulse performances of grounding grids for substations considering soil ionization," IEEE Transactions on Power Delivery, vol. 23, no. 2, pp. 667-675, 2008.

[8] B.R. Gupta, and B. Thapar, "Impulse impedance of grounding grids," IEEE Transactions on Power Apparatus and Systems, vol. 99, no. 6, pp. 2357-2362, 1980.

[9] Q. Chen, H. Zhang, J. Yin, W. Sima. S. Huang, P. Sun, and Y. Yu, "Parameters analysis of measured lightning overvoltages from a substation," IEEE International Conference on High Voltage Engineering and Application, pp. 1-4, 2018.

[10] R. P. Sodre, B. L. Pereira, L. L, Sidrim, J. F.Almeida, and C. L. S.S. Sobrinho, "Optimization of grounding grids design for a square-shaped mesh,” IEEE Latin America Transactions, vol. 16, no. 1, pp. 135-139, 2018.

[11] A. B. Patel, and K. Velani, "Digital application for grounding grid design calculations of substation," 2017 Innovations in Power and Advanced Computing Technologies (i-PACT), pp. 1-6, 2017.

[12] Y.M. Yi, M.F. Peng, H.T. Hai, and Y. H. Yuan, "Optimal design of grounding grids based on genetic algorithm," Third International Conference on Genetic and Evolutionary Computing, pp. 129-132, 2009.

[13] A. Kumar, V. Kumar, and P. A. Ashok, "Unequally spaced grounding grid designed from equally spaced grounding grid for 220/132kV Substation," International Conference on Advances in Communication and Computing Technology, pp. 114-116, 2018.

[14] L.Huang, X. Chen, and H. Yan, "Study of unequally spaced grounding group," IEEE Transactions on Power Delivery, vol. 10, no. 2, pp. 716-722, 1995.

[15] O. E. Gouda, and A.Z. El. Dein, "Ground potential rise of faulty substations having equal and unequal spacing grounding grids conductors," IET Generation, Transmission \& Distribution, vol. 11, no. 1, pp. 18-26, 2017.

[16] X. Cao, G. Wu, R. Li, and J. Zhu, "Optimization function for grounding grid in uniform soil," Asia-Pacific Power and Energy Engineering Conference, pp. 1-3, 2012.

[17] G. Karnas, G. Maslowski and R. Ziemba, and S. Wyderka, "Influence of different multilayer soil models on grounding system resistance," IEEE International Conference on Lightning Protection (ICLP), pp. 1-4,2012.

[18] Y. Li, J. Ma, F. P. Dawalibi, and J. Zhang, "Power grounding safety: copper grounding system vs. steel grounding system," IEEE International Conference on Power System Technology, pp. 1-6, 2006.

[19] G. Poulimenos, K.D. Damianaki, C.A. Christodoulou, V.P. Androvitsaneas, and I.F. Gonos, "Examination of the Effectiveness of the grounding systems of distribution substations," IEEE International Conference on High Voltage Engineering and Application (ICHVE), pp. 1-4, 2018.

[20] R.S. Ferraz, S.G.M Oliveira, S.B Oliveira, and W.P Calixto, "Analysis of the soil impedance in high frequencies using an electric impulse generator prototype," IEEE $16^{\text {th }}$ International Conference on Environment and Electrical Engineering, pp. 1-4, 2016.

[21] Williams, E., et al, "Application of geoelectric resistivity to determine soil moisture distrivution," American Journal of Engineering Research, vol. 7, no. 5, pp. 113-124, 2018.

[22] M. Mokhatri and Z. Abdul-Malek, "The effect of grounding electrode parameters on soil ionization and transient grounding resistance using electromagnetic field approach,” Appl. Mech. Mater., vol. 554, pp. 628-632, 2014.

[23] M. Mokhtari, Z. Abdul-Malek, and G. B. Gharehpetian, "A critical review on soil ionisation modelling for grounding electrodes,” Arch. Electr. Eng., vol. 65, no. 3, pp. 449-461, 2016.

[24] M. Mokhtari, Z. Abdul-Malek, and Z. Salam, "An improved circuit-based model of a grounding electrode by considering the current rate of rise and soil ionization factors," IEEE Transaction on Power Delivery-., vol. 30, no. 1, pp. 211-219, 2015.

[25] M. Mokhtari, Z. Abdul-Malek, and Z. Salam, "The effect of soil ionization on transient grounding electrode resistance in non-homogeneous soil conditions," Int. Trans. Electrical Energy Systems, vol. 26, no. 7, pp. 1462-1475, 2016.

[26] M. Mokhtari, Z. Abdul-Malek, and G. B. Gharehpetian, "A new soil ionization model for grounding electrodes," Int. Trans. Electrical Energy Systems., vol. 27, no. 3, pp. 1-15, 2017. 